\title{
UTILIZACÃO DE INDICADORES DE DESEMPENHO FINANCEIROS EM HOTÉIS NO SUL DO BRASIL
}

USE OF FINANCIAL PERFORMANCE INDICATORS IN HOTELS IN THE SOUTH OF BRAZIL UTILIZACIÓN DE INDICADORES DE DESEMPEÑO FINANCIERO EN HOTELES EN EL SUR DE
BRASIL

João Teles Professor das Faculdades Energia de Administração e Negócios (FEAN) Mestre em Contabilidade - Universidade Federal de Santa Catarina Especialização em Administração Tributária - Universidade Castelo Branco Bacharel em Ciências Contábeis - Universidade Federal de Santa Catarina E-mail: joaotele.contab@gmail.com

Rogério João Lunkes Professor da Universidade Federal de Santa Catarina Doutor em Engenharia de Produção - Universidade Federal de Santa Catarina Mestre em Engenharia de Produção - Universidade Federal de Santa Catarina Bacharel em Ciências Contábeis - Universidade Federal de Santa Catarina E-mail: lunkes@cse.ufsc.br

Roberto Kern Gomes Universidade Federal de Santa Catarina Mestre Administração de Empresas - Universidade do Estado de Santa Catarina Especialista em Administração de Empresas - Universidade Independente - Lisboa Bacharel em Ciência da Computação - Universidade do Estado de Santa Catarina E-mail: roberto.gomes@ibge.gov.br

Data de Submissão: 30/10/2012

Data de Aprovação: 13/08/2013

RESUMO

A presente pesquisa tem como objetivo identificar e analisar as medidas ou os indicadores financeiros utilizados por hotéis do Sul do Brasil. Para atingir este objetivo, uma pesquisa empírica foi realizada por meio de questionário aplicado a 23 hotéis na Região Sul. O estudo revela que o principal indicador financeiro utilizado é o RevPAR, com 52\%, Margem de lucro operacional, com 17\% e GOP, com 13\%, além de Diária média, Grau de Insolvência, Capital próprio e liquidez e PAX - Receita total por PAX, com 4,5\%, respectivamente. O estudo revela oportunidades para os hotéis utilizarem indicadores como o EBITDA, ROI e EVA. Como pesquisas futuras, sugerem-se: (i) identificar o perfil dos indicadores não financeiros, (ii) ampliar a amostra para outros hotéis da região sul e de outras regiões do Brasil, e (iii) desenvolver estudos de casos sobre avaliação de desempenho para hotéis.

PALAVRAS-CHAVES: Indicadores financeiros. Avaliação de desempenho. Hotéis.

\begin{abstract}
This research aims to identify and analyze the measures or financial indicators used by hotels in the South of Brazil. Empirical research was conducted through a questionnaire applied to 23 hotels in the region in the South region. The study reveals that the main financial indicator used is the REVPAR, with
\end{abstract}


$52 \%$, operating profit margin, with $17 \%$, and GOP, with $13 \%$, as well as the Daily the average, Degree of insolvency, Equity and Liquidity and PAX - total revenue by PAX with 4.5\%, respectively. The study reveals opportunities for the hotels to use indicators such as EBITDA, ROI and EVA. Suggested themes for further research are: (i) identifying the profile of non-financial indicators, (ii) expanding the sample to other hotels in the South and other regions of Brazil, and (iii) developing case studies on performance evaluation for hotels.

KEYWORDS: Financial indicators. Performance evaluation. Hotels.

\section{RESUMEN}

La presente investigación tiene como objetivo identificar y analizar las medidas o los indicadores financieros utilizados por hoteles del Sur de Brasil. Para alcanzar este objetivo se realizó una pesquisa empírica por medio de un cuestionario aplicado a 23 hoteles en la Región Sur. El estudio revela que el principal indicador financiero utilizado es el REVPAR con el 52\%, Margen de lucro operacional con el 17\% y GOP con el $13 \%$, además de Tarifa Diaria Promedio, Grado de Insolvencia, Capital Propio y Liquidez y PAX - Ingreso total por $\mathrm{PAX}$, con el 4,5\%, respectivamente. El estudio revela oportunidades para que los hoteles utilicen indicadores como el EBITDA, ROI y EVA. Como investigaciones futuras, se sugiere: (i) identificar el perfil de los indicadores no financieros, (ii) ampliar la muestra agregando otros hoteles de la región sur y de otras regiones de Brasil, y (iii) desarrollar estudios de casos sobre evaluación de desempeño para hoteles.

PALABRAS CLAVE: Indicadores financieros. Evaluación de desempeño. Hoteles.

\section{INTRODUÇÃO}

Segundo projeções da Organização Mundial do Turismo (OMT), as chegadas internacionais, ou seja, o número de visitantes que vêm de outros países deve alcançar, globalmente, o montante de 1,6 bilhões de passageiros até o ano de 2020. Esta é a previsão do número total de turistas viajando pelo mundo naquele ano.

O turismo já representa mais de $6 \%$ do comércio mundial, superior, por exemplo, à comercialização de produtos agrícolas. O Brasil teve em 2010 um número de 7.902.531 desembarques de passageiros internacionais e que geraram uma receita de US $\$ 5,9$ bilhões (LUNKES; ROSA, 2011).

O setor turístico e hoteleiro é uma área cada vez mais global, dinâmica e competitiva, o que tem levado a um aumento da rivalidade internacional (BARROSO; FLORES, 2006).

Assim, o setor hoteleiro, de uma forma geral, está imerso em um ambiente altamente competitivo e necessita de informações precisas e fidedignas para a adequada gestão das atividades. As empresas hoteleiras, como qualquer outra organização, podem se utilizar de medidas ou indicadores financeiros para gerar informações para o processo de tomada de decisão de seus gestores, visando melhorar o desempenho do negócio.

Contudo, pouco se sabe sobre gerenciamento em turismo, principalmente em empresas hoteleiras, o que sugere a necessidade de ampliar o conhecimento sobre o contexto gerencial e de desempenho de empresas do setor (PAVLATOS; PAGGIOS, 2009).

Visando explorar esta lacuna encontrada na literatura, o objetivo do trabalho é identificar e analisar as medidas ou os indicadores financeiros utilizados por hotéis do Sul do Brasil para apoio à gestão destes empreendimentos. Para apresentar esta pesquisa, o presente artigo está assim estruturado, a partir desta introdução, apresenta-se a base teórica, seguida pela metodologia, resultados, conclusões e referências. 
FUNDAMENTAÇÃO TEÓRICA

Considerando que a meta primária de todo hotel é obter lucro condizente ao capital investido e que para alcançar esta meta é necessário um conjunto de ações relacionadas ao desempenho financeiro e operacional, estas necessidades dos hotéis podem envolver medidas para gerenciar os objetivos e as atividades utilizadas para obter resultados que atendam às expectativas dos gestores e stakeholders.

Os resultados obtidos devem permitir ao hotel prover um retorno adequado aos seus acionistas e investidores, pagar os credores e recompensar adequadamente os colaboradores, além de sustentar o crescimento. Consequentemente, para manter um nível de desempenho que proporcione o resultado esperado, os gestores necessitam de um conjunto de medidas e indicadores para controlar aspectos financeiros e não financeiros.

Medir desempenho ou implementar um conjunto de indicadores de desempenho pode ser considerado um processo estruturado para coletar, descrever e representar dados, a fim de gerar informações sobre múltiplas dimensões de desempenho para diferentes usuários (BITICI, 1997; NEELY; ADMS; KENNERLY, 2002).

Neste contexto, os indicadores econômico-financeiros são fundamentais para a gestão e tomada de decisões em hotéis (MOSIMANN; FISCH, 1999; ALMEIDA; PARISI; PEREIRA, 2001; PELEIAS, 2002; SANTOS et al., 2005; KHATCHATOURIAN; TRETER, 2010)

Para gerenciar empresas hoteleiras, pode-se utilizar um conjunto de medidas de desempenho financeiras, como EVA e retorno sobre investimento, visando avaliar o reultado do negócio, bem como para informar investidores e credores, como instituições financeiras, investidores e acionistas. Para tanto, os hotéis podem selecionar indicadores adequados a sua estratégia de gestão. No Quadro 1, apresenta-se um conjunto de medidas e indicadores financeiros descritos na literatura sobre hotelaria.

Quadro 1: Identificação de critérios de avaliação de desempenho de hotéis

\begin{tabular}{|c|c|}
\hline Celistino (2003). & $\begin{array}{l}\text { Lucro Contábil } \\
\text { Ebitda - Resultados antes de Juros, Impostos, Depreciação e Amortização. } \\
\text { EVA (Valor Econômico Agregado) } \\
\text { MVA (Valor de Mercado Agregado). }\end{array}$ \\
\hline $\begin{array}{l}\text { Machado, } \\
\text { Machado e } \\
\text { Holanda (2007) }\end{array}$ & $\begin{array}{l}\text { Rentabilidade; Receita total; Margem de lucro; Participação no mercado; Margem } \\
\text { de lucro; Evolução da lucratividade; Fluxo de caixa; Retorno sobre o investimento; } \\
\text { Valor econômico agregado; } \\
\text { Outros indicadores não financeiros: rotatividade de empregados; Atendimento, } \\
\text { Captação e Retenção de clientes; Evolução do número de funcionários; Número } \\
\text { de reclamações; Investimento em propaganda; Investimento em treinamento; } \\
\text { Investimento em móveis, utensílios e equipamentos; Número de cancelamentos } \\
\text { de reservas. }\end{array}$ \\
\hline $\begin{array}{l}\text { Suárez e Ferrer, } \\
\text { (2008). }\end{array}$ & Taxa de retorno financeiro, Margem de lucro bruto; Margem de lucro operacional. \\
\hline $\begin{array}{l}\text { Planas, Rebull e } \\
\text { Clavé (2008) }\end{array}$ & $\begin{array}{l}\text { ADR (Average Daily Rate) ou tarifa média por habitação; } \\
\text { RevPar (Revenue per Available Room) ou ingresso por habitação disponível; } \\
\text { Taxa ou Coeficiente de ocupação. }\end{array}$ \\
\hline
\end{tabular}




\begin{tabular}{|l|l|}
\hline $\begin{array}{l}\text { Ricci e Escrivão } \\
(2009)\end{array}$ & $\begin{array}{l}\text { Margem bruta; Geração de caixa; Vendas; Rentabilidade sobre o patrimônio } \\
\text { líquido; Valor Econômico Agregado; Liquidez Corrente; Crescimento da Receita. }\end{array}$ \\
\hline $\begin{array}{l}\text { KhatchatoUrian e } \\
\text { Treter (2010 }\end{array}$ & $\begin{array}{l}\text { Retorno sobre capital próprio: Giro de Ativo, Lucratividade sobre vendas, Retorno } \\
\text { sobre ativos, Participação do capital de terceiros. } \\
\text { imediata. }\end{array}$ \\
\hline $\begin{array}{l}\text { Callado, Callado pagamento: Liquidez geral, liquidez corrente, liquidez seca, liquidez } \\
\text { e Holanda } \\
\text { (2010) }\end{array}$ & $\begin{array}{l}\text { Earticipação no mercado; Taxa média de ocupação; Evolução do número de } \\
\text { clientes; } \\
\text { Evolução do número de empregados; Investimento em propaganda; } \\
\text { E outros indicadores não financeiros relacionados a clientes e qualidade dos } \\
\text { serviços. }\end{array}$
\end{tabular}

Fonte: Elaborado pelos autores.

Foram listados alguns exemplos de medidas de desempenho financeiro que o hotel pode utilizar. Porém, cabe ressaltar que não é recomendado utilizar excesso de indicadores de desempenho. Os gestores devem selecionar aqueles consistentes com a estratégia do hotel, uma vez que utilizar muitas medidas de desempenho pode refletir falta de foco e gerar confusão (KAPLAN; NORTON, 1997).

Lunkes e Rosa (2011) entendem que, dentre os indicadores ou as medidas que influem sobre o lucro e que possibilitam medir os resultados do hotel, destacam-se o ROI, EVA, RevPor, RevPar, entre outros, explícitos no Quadro 2.

Quadro 2: Medidas ou indicadores financeiros

\begin{tabular}{|c|c|}
\hline \multirow{2}{*}{$\begin{array}{l}\text { Medidas Relacionadas às } \\
\text { Receitas }\end{array}$} & RevPor - Revenue por Ocupied Room \\
\hline & RevPar - Revenue per Available Room \\
\hline \multirow{6}{*}{$\begin{array}{l}\text { Medidas Relacionadas ao } \\
\text { Resultado Financeiro e } \\
\text { Econômico }\end{array}$} & RevPar Yield - Hotel RevPAR / Segment RevPAR \\
\hline & Flowthorough model \\
\hline & $\begin{array}{l}\text { EBITDA - Resultados antes de Juros, Impostos, Depreciação e } \\
\text { Amortização. }\end{array}$ \\
\hline & Resultado Operacional Bruto por Departamento \\
\hline & ROI - Return on Investment \\
\hline & EVA - Economic Value Added \\
\hline
\end{tabular}

Fonte: Lunkes e Rosa (2011).

A Receita total por habitação ocupada - RevPor é calculada dividindo-se a receita total gerada pelo hotel pelo número de habitações ocupadas. Já as Receitas totais por habitação disponível RevPar é calculada dividindo-se a receita total gerada pelo hotel (habitações mais todas as demais receitas complementares) pelo número de habitações disponíveis. Assim, o RevPar mede a receita gerada por cada habitação. Esse indicador também é utilizado na avaliação de investimentos: o RevPar Yield - que é calculado dividindo o RevPar do hotel pelo RevPar do setor.

O Flowthorough model é obtido dividindo-se o valor absoluto do incremento das vendas (em relação ao orçamento) e ao incremento do resultado operacional bruto. O EBITDA é um indicador de desempenho usado para analisar a rentabilidade das empresas, porque elimina os efeitos de 
financiamentos e os procedimentos contábeis sobre lucro. A medida representa o lucro operacional informado antes de juros, tributos, depreciação e amortização.

O Resultado Operacional Bruto por Departamento é uma medida da contribuição líquida de cada departamento ao resultado global do hotel, depois de deduzir das receitas os custos ou os gastos possíveis de serem alocados diretamente.

O ROI - Retorno sobre o Investimento é frequentemente usado como o último teste de eficiência do hotel. Compreendendo bem as variáveis que afetam a rentabilidade, os gestores podem focalizar seus esforços para melhorá-la. De maneira geral, deve-se relacionar o lucro com algum valor que expresse a dimensão relativa do mesmo, para analisar o desempenho da unidade no período.

Para avaliar melhor a dimensão do lucro do hotel, pode-se compará-lo ao nível de ocupação, valor do ativo total, valor do patrimônio líquido, valor do ativo operacional, entre outros, dependendo da informação desejada. Os parâmetros aceitáveis para o ROI na hotelaria no Brasil estão entre 10 a $15 \%$ ao ano (LUNKES; ROSA, 2011).

O Indicador de Agregação de Valor mede como o hotel está reduzindo o investimento e consequentemente o custo de capital e melhorando os lucros. A composição do capital, terceiros e próprios geralmente afetam o custo do capital. Assim, os hotéis devem examinar o custo de seu capital, isto inclui níveis de equilíbrio e eliminação de recursos não produtivos.

O EVA é uma das medidas de desempenho utilizadas na avaliação do centro de investimento. Em resumo, mede a riqueza agregada pela unidade, ou seja, o lucro operacional deve ser maior que o custo do capital. Embora seja uma das principais medidas de avaliação da riqueza dos acionistas, os hotéis podem utilizá-lo interiormente como parte do pagamento de incentivos, conduzindo ao comportamento desejado (EHRBAR, 1999).

\section{METODOLOGIA}

Esta pesquisa tem característica descritiva, pois procura descrever e analisar a utilização de indicadores financeiros no setor de hotelaria. Trata-se de estudo ex post facto, no qual o pesquisador não tem controle sobre as variáveis, no sentido de poder manipulá-las, pode apenas relatar o que aconteceu ou que está acontecendo. Utiliza-se de dados primários para obter as informações, visando atingir o objetivo proposto (COOPER; SCHINDLER, 2003).

O questionário foi construído para atender aos objetivos de uma dissertação de mestrado, compondo-se de 99 variáveis investigadas. O presente trabalho é um recorte desse trabalho, prendendo-se aos objetivos de caracterizar os hotéis da amostra e identificar o perfil dos indicadores de desempenho financeiro utilizados.

O desenvolvimento das questões aplicadas ocorreu de forma secundária, por terem sido adaptadas dos estudos de Sathe (1982); Burgess (1994); IMA (1996); Burns e Yazdifar (2001); Rouwelaar e Bots (2008a); Rouwelaar e Schaepkens (2008b), que pesquisaram hotéis em diferentes partes do mundo, conforme Quadro 3.

Quadro 3: Perfil do questionário utilizado na pesquisa

\begin{tabular}{|l|l|}
\hline \multirow{4}{*}{$\begin{array}{l}\text { Caracterização dos } \\
\text { hotéis da amostra }\end{array}$} & Classificação dos hotéis por número de UH`s disponíveis \\
\cline { 2 - 2 } & Classificação das empresas por número de funcionários \\
\cline { 2 - 2 } & Idade dos hotéis \\
\cline { 2 - 2 } & $\begin{array}{l}\text { Tipo do hotel } \\
\text { Desempenho organizacional dos hotéis: Taxa média de ocupação (2010) e } \\
\text { Comportamento do resultado operacional }\end{array}$ \\
\hline
\end{tabular}




\begin{tabular}{|l|l|}
\hline \multirow{4}{*}{$\begin{array}{l}\text { Indicadores de } \\
\text { Desempenho } \\
\text { Utilizados }\end{array}$} & RevPAR - Receita por UH disponível \\
\cline { 2 - 2 } & Margem de lucro operacional \\
\cline { 2 - 2 } & GOP - Lucro operacional bruto \\
\cline { 2 - 2 } & DM - Diária média \\
\cline { 2 - 2 } & Lucratividade \\
\cline { 2 - 2 } & DRE - Grau de Insolvência, capital próprio e liquidez \\
\hline
\end{tabular}

Fonte: Elaborado pelos autores.

O questionário é composto por proposições investigativas do tipo Likert, para as quais são atribuídos valores - 1 significa a impressão menos favorável e 5 a mais favorável (COOPER; SCHINDLER, 2003).

A população utilizada para a verificação da percepção dos controllers de hotéis das cidades de Curitiba, Florianópolis e Porto Alegre parte da relação de hotéis associados à Associação Brasileira da Indústria de Hotéis (ABIH) por ser um representante oficial do segmento hoteleiro. Após o aceite verbal, foram enviados os questionários via e-mail, obtendo-se a amostra de 23 hotéis, os quais aceitaram responder às proposições.

A coleta de dados foi realizada durante os meses de novembro de 2010 e março de 2011. Para verificar a presença do controller nos hotéis, foi perguntado aos atendentes, por contato telefônico, sobre a presença do departamento de controladoria. Em caso negativo, indagou-se sobre o contador gerencial ou responsável por departamento financeiro, no sentido de que os respectivos profissionais exercem suas funções, não se apegando a denominações (SÁ, 2009).

O tratamento estatístico estrutura-se a partir da descrição dos dados com base em medidas de dispersão, em que se executam os cálculos da média; mediana; e desvio padrão, para posterior análise.

\section{RESULTADOS}

Nesta etapa da pesquisa apresentam-se os resultados obtidos quanto ao perfil dos hotéis da amostra e dos indicadores de desempenho utilizados.

\section{CARACTERIZAÇÃO DOS HOTÉIS DA AMOSTRA}

Para a identificação e classificação da amostra, elaborou-se o questionário de tal forma que se pudesse, a partir dos resultados, conhecer o porte empresarial por meio de leitos ofertados e número de funcionários; tipo de hotel (se pertencente à rede hoteleira); desempenho organizacional (taxa de ocupação, comportamento do lucro e dos indicadores financeiros utilizados).

Com isso, buscam-se informações sobre os hotéis da amostra investigada, caracterizando e conhecendo o perfil do grupo de estudo e o comportamento de variáveis que podem ter influência nos resultados.

Não são identificados os hotéis participantes, bem como os profissionais respondentes, uma vez que essa foi a condição de alguns profissionais para a participação na pesquisa. Assim, respeitando o sigilo das informações prestadas e a equidade do tratamento ao grupo de pesquisa, tais informações serão mantidas em poder do pesquisador.

\section{Classificação dos hotéis por número de UH`s disponíveis}

De acordo com a metodologia adotada para este estudo, consideraram-se apenas os hotéis com oferta superior a cem unidades habitacionais (UH's). Conforme a Tabela 1, a maioria dos hotéis (15) 
possui entre cem e duzentos UH's e apenas dois hotéis destoam do grande grupo, apresentando porte superior a trezentas UH's.

Tabela 1: Quantidade de UH'S dos hotéis pesquisados

\begin{tabular}{lllll}
\hline Número de UH's & Frequência & $\%$ & $\%$ acumulada & $\begin{array}{l}\text { Estatística descritiva para o } \\
\text { grupo }\end{array}$ \\
\hline De 100 até 150 & 7 & $30,4 \%$ & $30,4 \%$ & Média - 206,3 \\
De 151 a 200 & 8 & $34,8 \%$ & $65,2 \%$ & Desvio-padrão - 124,5 \\
De 201 até 250 & 4 & $17,4 \%$ & $82,6 \%$ & Mediana - 188 \\
De 251 até 300 & 2 & $8,7 \%$ & $91,3 \%$ & - \\
Acima de 300 & 2 & $8,7 \%$ & $100,0 \%$ & \\
\hline TOTAL & 23 & $100 \%$ & - &
\end{tabular}

Fonte: Elaborado pelos autores.

Pelo tratamento estatístico descritivo, observa-se que a média do grupo é de 206,3 UH's,

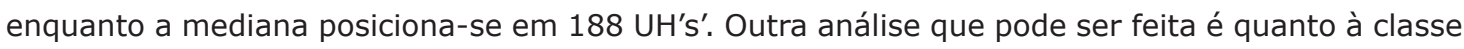
modal do grupo e, neste caso, oito hotéis estão entre 151 e 200 UH's.

\section{Classificação das empresas por número de funcionários}

Outra distinção de porte comumente utilizada diz respeito à quantidade de funcionários do empreendimento. À época da pesquisa, os empreendimentos estavam assim apresentados por classes, assim como a frequência acumulada e estatística descritiva para o grupo:

Tabela 2 - Número de funcionários dos hotéis pesquisados

\begin{tabular}{lllll}
\hline $\begin{array}{l}\text { Número de } \\
\text { funcionários }\end{array}$ & Frequência & $\%$ & $\%$ acumulada & $\begin{array}{c}\text { Estatística descritiva } \\
\text { para o grupo }\end{array}$ \\
\hline Até 50 & 1 & $4,3 \%$ & $4,3 \%$ & \\
De 51 até 100 & 7 & $30,4 \%$ & $34,8 \%$ & Média - 157,7 \\
De 101 até 150 & 6 & $26,1 \%$ & $60,9 \%$ & Desvio-padrão - 130,5 \\
De 151 até 200 & 5 & $21,7 \%$ & $82,6 \%$ & Mediana - 145 \\
De 201 até 250 & 1 & $4,3 \%$ & $87,0 \%$ & \\
De 251 até 300 & 1 & $4,3 \%$ & $91,3 \%$ & - \\
Acima de 300 & 2 & $8,7 \%$ & $100,0 \%$ & - \\
\hline TOTAL & 23 & $100,0 \%$ & - &
\end{tabular}

Fonte: Elaborado pelos autores.

A maior concentração de respostas ocorreu nas faixas de 51 a 200 funcionários, com destaque à classe modal de 51 a 100 funcionários. Porém, a média e a mediana podem ser notadas na classe entre 101 e 150 funcionários.

Como o setor hoteleiro apresenta, em grande parte, características de sazonalidade devido aos períodos de férias e alta temporada, buscou-se um questionamento complementar acerca do contingente de pessoal temporário ou terceirizado, cujos resultados estão evidenciados na Tabela 3. 
Tabela 3 - Número de funcionários temporários e/ou terceirizados

\begin{tabular}{llll}
\hline $\begin{array}{l}\text { No de func. temporários e/ou } \\
\text { terceirizados }\end{array}$ & Frequência & $\%$ & $\%$ acumulada \\
\hline Nenhum & 5 & $21,7 \%$ & $21,8 \%$ \\
Até 10 & 5 & $21,7 \%$ & $43,5 \%$ \\
De 11 a 20 & 6 & $26,2 \%$ & $69,6 \%$ \\
De 21 a 40 & 5 & $21,7 \%$ & $91,3 \%$ \\
De 41 a 100 & 1 & $4,3 \%$ & $95,7 \%$ \\
Até 200 & 1 & $4,3 \%$ & $100,0 \%$ \\
\hline TOTAL & $\mathbf{2 3}$ & $\mathbf{1 0 0} \%$ & - \\
\hline
\end{tabular}

Fonte: Elaborado pelos autores.

A grande maioria dos hotéis da amostra $(91,3 \%)$ possui até quarenta funcionários temporários e/ou terceirizados, enquanto quantidades mais expressivas são verificadas nos dois hotéis de maior porte, identificados na análise de quantidade de UH's.

\section{Idade dos hotéis}

O Gráfico 1 evidencia como as empresas estão distribuídas quanto ao tempo, em anos, em que desenvolvem suas atividades. Também é utilizada nesse item a segmentação dos resultados por faixas.

Gráfico 1 - Faixa etária dos hotéis da amostra

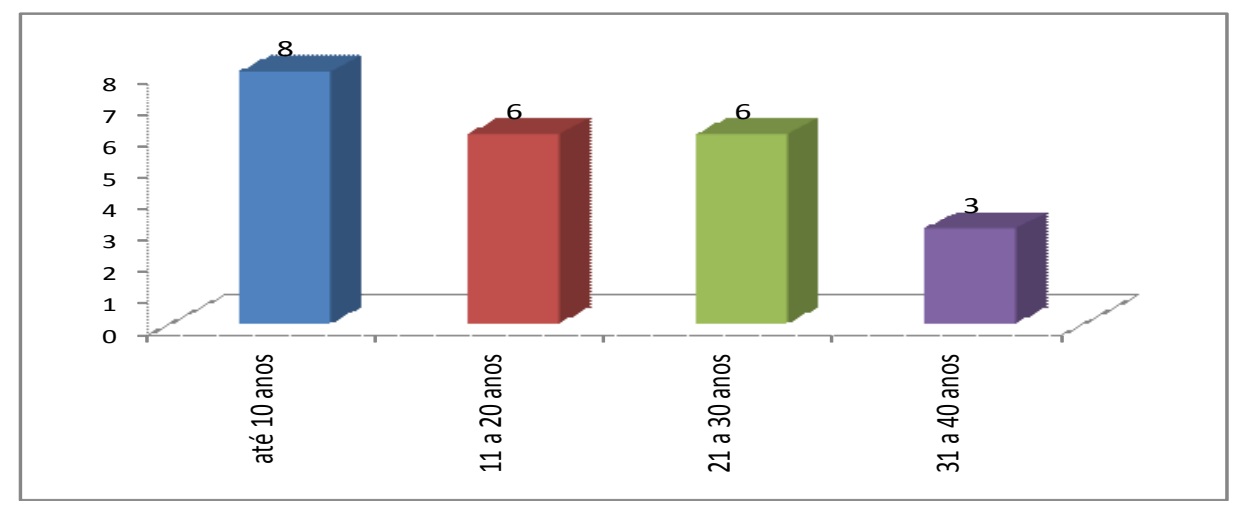

Fonte: Elaborado pelos autores.

Os resultados demonstram que a maior incidência da amostra é de empresas com até dez anos de existência, perfazendo $34,8 \%$ dos hotéis da pesquisa. No Gráfico 1, percebem-se seis empresas com até vinte anos e o mesmo número de empresas com até 30 anos.

Os hotéis mais antigos da pesquisa (3) estão na faixa entre trinta e quarenta anos, revelando a ausência de empresas com mais de quarenta anos, caracterizando uma amostra de organizações relativamente jovens. As idades estão compreendidas entre três (3) e trinta e oito anos.

Tipo do hotel (pertencente à rede hoteleira ou ao empreendimento único)

Quanto à caracterização dos hotéis, de acordo com sua natureza empresarial, perguntou-se se o estabelecimento pertence à rede hoteleira ou é empreendimento único. A amostra apresenta-se dividida entre os dois tipos, conforme Gráfico 2. 
Gráfico 2 - Tipo do hotel (rede hoteleira/ empreendimento único)

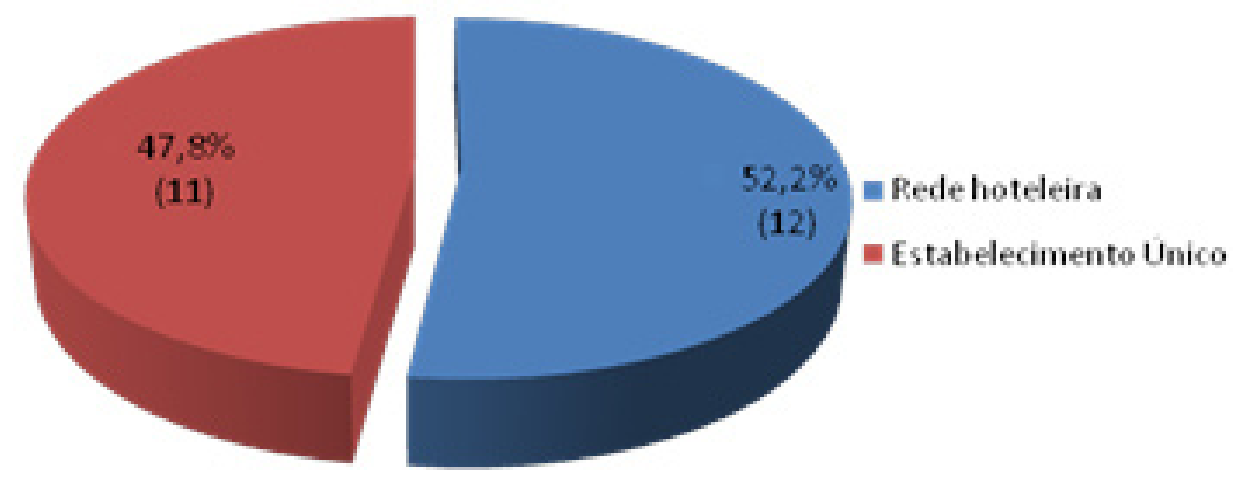

Fonte: Elaborado pelos autores.

Desse modo, doze hotéis investigados pertencem à rede de hotéis, enquanto outros onze são empreendimentos únicos. Cabe observar que, nos hotéis pertencentes à rede hoteleira, buscou-se a interrogação com o profissional responsável pela unidade hoteleira em que foi aplicada a pesquisa.

\section{Desempenho organizacional dos hotéis}

Para se analisar o desempenho organizacional das empresas, investigou-se sobre a taxa média de ocupação no ano de 2010 e o comportamento do resultado operacional.

\section{a) Taxa média de ocupação (2010)}

Segundo dados da STR Global (2011), a taxa média de ocupação da hotelaria brasileira em 2010 foi de $60,1 \%$. Esse número representa um aumento de 6,5\% em relação ao ano anterior. De acordo com o Fórum dos Operadores Hoteleiros do Brasil - FOHB (2011), a taxa de ocupação média para os hotéis do sul do Brasil em 2010 foi de 54,32\%.

Nos hotéis catarinenses, essa taxa foi menor, de 44,66\%, conforme a ABIH/SC. No Paraná, a Secretaria de Turismo do Estado apresenta dados até 2009, com a taxa média de ocupação nesse ano de 35,1\%. Para o Estado do Rio Grande do Sul não se encontraram dados consolidados, todavia, o Sindicato de Hotelaria e Gastronomia de Porto Alegre (SINDPOA) fornece dados da capital gaúcha, findando o ano de 2010 com a taxa de ocupação em 69,48\%.

A amostra desta questão (23 empresas) apresenta taxa média de ocupação de $61 \%$, sendo condizente com a média do setor apresentada anteriormente. Neste item pode se observar, de maneira geral, que a taxa de ocupação média dos hotéis no último ano oscilou entre $43 \%$ e $76 \%$, desconsiderando um estabelecimento que apresentou $32 \%$.

\section{b) Comportamento do resultado operacional}

Por considerar de difícil acesso as informações envolvendo dados internos, conforme mencionado anteriormente, abordou-se esse quesito de maneira diferente, analisando apenas o comportamento do resultado operacional nos últimos anos (3 a 5 anos).

Entende-se como resultado operacional em termos contábeis aquele obtido depois de deduzidas da receita líquida os custos dos serviços prestados, despesas de pessoal, administrativas e financeiras. O Gráfico 3 revela os resultados levantados. 
Gráfico 3: Comportamento do lucro operacional nos últimos anos (3 a 5 anos)

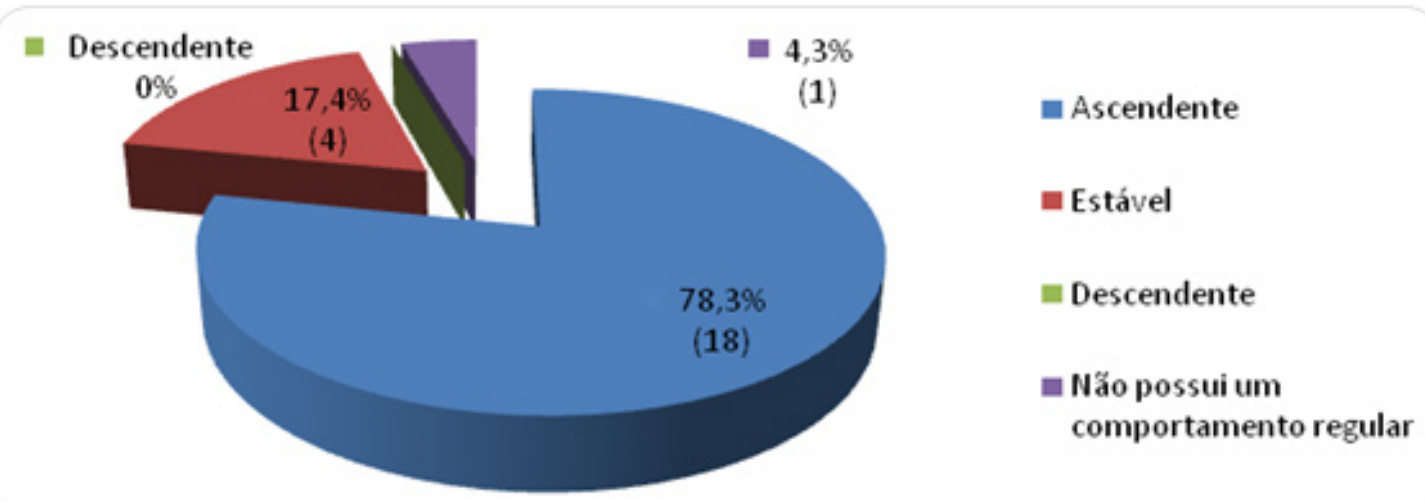

Fonte: Elaborado pelos autores.

Quase $80 \%$ das empresas pesquisadas percebem um comportamento ascendente para o resultado operacional nos últimos anos, podendo indicar práticas de gestão eficientes e/ou também o aquecimento da demanda hoteleira, decorrente do aumento do poder aquisitivo dos brasileiros e da divulgação da imagem do país no exterior (FOHB, 2011).

Apenas um hotel não indicou tendências para o lucro operacional, afirmando não possuir um comportamento regular nos últimos anos, representando 4,3\% da amostra. Outros quatro questionados expõem que o hotel teve um comportamento estável, não apresentando maiores variações.

De maneira geral, esse resultado vai ao encontro das expectativas para o setor do turismo e da hotelaria, que vem apresentando expansão nos últimos anos, mostrando-se um setor em aquecimento na economia (FOHB, 2011).

Os resultados apresentados acerca do desempenho operacional dos hotéis sugerem que a amostra possui um comportamento positivo no que tange à ocupação e ao aumento do lucro operacional.

\section{Indicadores de desempenho utilizados}

No intuito de identificar as práticas utilizadas para avaliação do desempenho financeiro dos hotéis, indagou-se sobre qual o indicador de desempenho financeiro mais utilizado pelos hotéis e pelo seu respectivo valor no último ano.

Por se tratar de um dado interno, apenas onze respondentes forneceram esses números. Todavia, no que se referem aos indicadores utilizados, vinte e três profissionais evidenciaram tais indicadores, identificados na Tabela 4.

Tabela 4: Principais indicadores financeiros utilizados pelos hotéis

\begin{tabular}{lll}
\hline Principais indicadores financeiros utilizados & Frequência & Percentual \\
\hline RevPAR - Receita por UH disponível & 12 & $52 \%$ \\
Margem de lucro operacional & 4 & $17 \%$ \\
GOP - Lucro operacional bruto & 3 & $13 \%$ \\
DM - Diária média & 1 & $4,5 \%$ \\
Lucratividade & 1 & $4,5 \%$ \\
DRE - Grau de Insolvência, capital próprio e liquidez & 1 & $4,5 \%$ \\
PAX - Receita total por PAX & 1 & $4,5 \%$ \\
\hline TOTAL & 23 & $100 \%$ \\
\hline
\end{tabular}

Fonte: Elaborado pelos autores. 
O RevPAR (receita por UH disponível) é um indicador específico do setor hoteleiro que representa a receita de hospedagem de um período dividida pela quantidade de UH's disponíveis nesse período.

De acordo com a Tabela 4, pode-se perceber que, entre os hotéis da amostra, o RevPAR é o principal indicador financeiro. Neste indicador, apenas quatro hotéis revelaram o valor, sendo que os valores apontados são os seguintes: R\$322, 144, 97, 39 e 93. Isto corrobora com estudos internacionais da Consultoria Deloitte (Ranking Global de Indicadores de Performance - Hotel Benchmark), que colocam o Rio de Janeiro na 74a posição em 2005, com RevPAR de U\$ 87 (aproximadamente $\mathrm{R} \$ 140,00)$.

Estes resultados mostram que o hotel com o melhor RevPAR ( $\mathrm{R}$ \$ 322) está entre os melhores resultados em nível mundial, próximo das médias de cidades como Veneza (Itália), Dubai (Arábia Saudita) e Paris (França). A média europeia em 2007 foi de U\$ 85 (aproximadamente R\$ 200,00).

Em seguida, de acordo com o maior número de respostas foi para 'margem de lucro operacional', um indicador contábil com base na Demonstração do Resultado do Exercício (DRE) com quatro respostas. Cabe expor que este não é um indicador específico do setor, podendo ser utilizado por qualquer empresa que faz uso da DRE. Os cinco hotéis que responderam à questão relacionada ao valor correspondente no último ano apontaram os seguintes percentuais: $20 \%, 27 \%, 27 \%, 30 \%$ e $38 \%$.

Com três citações, o GOP (Gross operating profit) é um indicador contábil que representa o lucro operacional bruto, considerando as receitas geradas menos o total de despesas operacionais e departamentais. Uma vertente desse indicador é o GOPPAR, que seria a divisão do GOP pela quantidade de UH's ofertadas. Este indicador é recomendado pelo (Sistema Uniforme de Contabilidade para o Setor Hoteleiro (USALI).

Outro indicador específico do setor, a diária média (DM), aparece com uma citação e pode ser representada pela receita de vendas dividida pelo volume de habitações vendidas (UH's). O valor apontado por um único hotel foi de $\mathrm{R} \$ 142,00$.

O PAX - Receita total por PAX também foi indicado por um hotel. Embora, este indicador não fazia parte das medidas financeiras listadas na questão, mas como a pergunta tinha no final um item aberto denominado "Outro(s)", este foi mencionado por uma empresa hoteleira.

Um fator bastante surpreendente em relação aos resultados é a não utilização de medidas financeiras amplamente abordadas na literatura e utilizadas em outros setores como o ROI - retorno sobre investimento e EVA - Valor Econômico Agregado. Além da ausência de citação do EBITDA, que a nível internacional faz parte do sistema contábil denominado de USALI - Uniform System of Accounts for the Lodging Industry.

\section{CONCLUSÕES E RECOMENDAÇÕES}

Perseguindo o objetivo do trabalho, buscou-se identificar e analisar as medidas ou os indicadores financeiros utilizados por hotéis do sul do Brasil. Para tanto, aplicou-se um questionário para identificar junto aos gestores de 23 hotéis dos estados de Santa Catarina, Paraná e Rio Grande do Sul.

O estudo revela que, na amostra, 52,2\% dos hotéis pesquisados são redes hoteleiras, dentre os quais $34,8 \%$ são hotéis de até 10 anos. Revela também que 37,8\% dos hotéis possuem entre 151 a 200 habitações; 30,4\%, possuem entre 51 a 100 funcionários; e 26,2,\% necessitam entre 11 e 22 empregados temporários/terceirizados.

Esses hotéis, no ano de 2010, obtiveram uma taxa média de ocupação de $61 \%$, estando, portanto, dentro da média nacional $(60,1 \%)$ e acima da média da região sul (54,32\%). Adicionalmente, verifica-se que o comportamento do lucro para a maioria dos hotéis é ascendente (78,3\%), o que pode indicar práticas gerenciais bem-sucedidas. Contudo, aponta-se aqui uma necessidade de aprofundamento de variáveis externas que podem influenciar este crescimento positivo.

Quanto aos indicadores de desempenho financeiro, os hotéis pesquisados utilizam primordialmente medidas relacionadas a lucro, tais como: RevPAR - Receita por UH disponível (52\%), Margem de lucro operacional (17\%), GOP - Lucro operacional bruto (13\%), DM - Diária média (4,5\%), Lucratividade, DRE - Grau de Insolvência (4,5\%), capital próprio e liquidez (4,5\%) e PAX - Receita total por PAX (4,5\%). 
O estudo revela oportunidades para os hotéis utilizarem indicadores mais robustos, relacionados ao desempenho econômico-financeiro, como o EBITDA - Resultados antes de Juros, Impostos, Depreciação e Amortização, ROI - Returno sobre Investimento e EVA - Valor Econômico Agregado.

Como pesquisas futuras, sugere-se: (i) uso de estudos de casos para testar o uso de sistema de avaliação de desempenho com indicadores financeiros e não financeiros, (ii) também ampliar a amostra da presente pesquisa para identificar o uso de indicadores financeiros e não financeiros, (iii) identificar o perfil de outros hotéis da região sul e de outras regiões brasileiras para identificar novas oportunidades práticas; (iv) verificar a correlação entre as medidas utilizadas com o desempenho econômico-financeiros dos hotéis pesquisados.

\section{REFERÊNCIAS}

ABIH - Associação Brasileira da Indústria de Hotéis. Disponível em: <www.abih-sc.com.br>. Acesso em: 20 fev. 2010.

ALMEIDA, L. B.; PARISI, C.; PEREIRA, C. A. In: CATELLI, Armando (Coord.). Controladoria: uma abordagem da Gestão Econômica - Gecon. São Paulo: Atlas, p. 343-355, 2001.

BARROSO, M.; FLORES, D. La competitividad internacional de los destinos turísticos: del enfoque macroeconómico al enfoque estratégico, Cuadernos de Turismo, n. 17, 2006, p. 7-24.

BITICI, U.S. Integrated Performance Measurement Systems - An Audit and Development Guide. The TQM Magazine, v. 9, n. 1, p. 46-53, 1997.

BURNS, J.; YAZDIFAR, H. Tricks or Treats. Financial Management, p. 33-35, 2001.

BURGESS, C. L. The Education and Training Needs of the Hotel Financial Controller. International Journal of Contemporary Hospitality Management, v. 06, n. 05, p. 09-13, 1994.

CALLADO, A.L.C.; CALLADO, A.A.C.; HOLANDA, F.M.A. Caracterizacion del uso de indicadores de desempeño no financieros en el sector hotelero. Estudios y perspectivas en turismo, v. 20, n.11, p. 876-890, 2011.

CELISTINO, M. S. Utilização de indicadores financeiros e nao-financeiros na gestão de hotéis no Rio Grande do Norte: Estudo sob a ótica do Balanced Scorecard. Dissertação de mestrado do Programa Multi-institucional e Inter-regional em Ciências Contábeis da Universidade Federal da Paraíba, de Pernambuco e do Rio Grande do Norte. 196 p, 2003

COOPER, D.R.; SCHINDLER, P.S. Métodos de Pesquisa em Administração. 7. ed. Porto Alegre: Bookman, 2003.

EHRBAR, A. EVA - Valor Econômico Agregado. Rio de Janeiro: Qualitymark, 1999.

FOHB - Fórum de Operadores Hoteleiros do Brasil. Disponível em: <www.fohb.com.br>. Acesso em: 02 de abril de 2011.

IMA - Institute of Management Accountants, 1996. Disponível em:<www.imanet.org>.

KAPLAN, R. S. NORTON, D. P. A. Estratégia em Ação - Balanced Scorecard. 7. ed. Rio de Janeiro: Campus, 1997.

KHATCHATOURIAN, O.; TRETER, J. Aplicação da Lógica Fuzzy para Avaliação Econômico-Financeira de Cooperativas de Produção. Revista de Gestão da Tecnologia e Sistemas de Informação. Journal of Information Systems and Technology Management. v. 7, n. 1, p.141-162, 2010.

LUNKES, R.J.; ROSA, F.S. Gestão Hoteleira. Curitiba: Juruá, 2011.

MACHADO, M.R.; MACHADO, M.A.V; HOLANDA, F.M.A. Indicadores de Desempenho Utilizados Pelo Setor Hoteleiro da Cidade de João Pessoa/PB: um estudo sob a ótica do Balanced Scorecard. Turismo - Visão e Ação - v. 9, n.3, p. 393-406 set. /dez. 2007.

MARTINS, G.A. Manual para elaboração de monografias e dissertações. 3. ed. São Paulo, Atlas, 2002. 
MOSIMANN, C. P.; FISCH, S. Controladoria. 2. ed. São Paulo: Atlas, 1999.

NEEDLES, Jr; BELVERD, E; CASCINI, K; KRYLOVA, T; MOUSTAFA, M. Strategy for Implemention of IFAC International Guideline n. 9. Journal of International Financial Management \& Accounting. $v$. 12 , p. 317-354, 2001.

NEELY, A.; ADAMS, C.; KENNERLY, M. The performance prism: the scorecard for measuring and managing business success. Prentice Hall. 2002.

PAVLATOS, O.; PAGGIOS, I. A survey of factors influencing the cost system design in hotels. International Journal of Hospitality Management. v 28, n. 02, p. 263-271, 2009.

PELEIAS, I. R. Controladoria: gestão eficaz utilizando padrões. São Paulo: Saraiva, 2002.

PLANAS, F. C.; REBULL, M. V. S.; CLAVÉ, S. A. Aproximación a lãs prácticas em Contabilidad de Gestión de La Industria de Parques Temáticos españoles. Revista iberoamericana de contabilidad de gestión, n. 11, p. 163-182, 2008.

RICCI, G.L.; ESCRIVÃO FILHO, E. Controle organizacional em empresas do setor hoteleiro: uma reflexão sobre a importância da medição de desempenho. Revista InGepro Inovaçao Gestao e Produção, 2009

ROUWELAAR, H., SCHAEPKENS, F. More effective by involvement in management: An empirical study about Dutch Financial Controllers working in the Health care sector. Breukelen: Financial Controllers in Health Care, 2008.

; BOTS, Jan. Business Unit controller involvement in management: An empirical study in the Netherlands. Breukelen: Financial Controllers in Health Care, 2008.

SÁ, A. L. de. Controladoria e contabilidade aplicada à administração. Curitiba: Juruá, 2009.

SANTOS, R.V; CASTELLANO, A.C. F; BONACIM, C. A G. O papel do controller em empresas de grande porte. Anais do IX Congresso Internacional de Custos - Florianópolis, SC, 28 a 30 nov. 2005.

SILVA, Lucileni Pereira. O papel do controller em empresas de grande porte. Anais do IX Congresso Internacional de Custos, Florianópolis, SC - 28 a 30 nov. 2005.

SATHE, V. Controller Involvement in Management. Prentice-Hall, 1982.

SETU/ PR - Secretaria de Estado do Turismo do Paraná. Disponível em: <www.setu.pr.gov.br>. Acesso em: 03 de abril de 2011.

SINDPOA - Sindicato de Hotelaria e Gastronomia de Porto Alegre. Disponível em: Acesso em: 03 de abril de 2011.

STR Global - STR Global. Disponível em: <www.strglobal.com.br>. Acesso em: 02 de abril de 2011.

SUÁREZ, H. B; FERRER, M.AL.; SUÁREZ, H.A. Indicadores de rentabilidad: herramientas para la toma decisiones financieras en hoteles de categoría media ubicados en Maracaibo. Revista de Ciencias Sociales (RCS) v. 14, n. 1, p. 88-109, Janeiro - Abril 2008. 